Article

\title{
Improvement of Survival over Time for Colorectal Cancer Patients: A Population-Based Study
}

\author{
Audrius Dulskas ${ }^{1,2, *(\mathbb{D})}$, Vytautas Gaizauskas ${ }^{3}$, Inga Kildusiene ${ }^{4}$, Narimantas Evaldas Samalavicius ${ }^{2,5,6}$ \\ and Giedre Smailyte ${ }^{4,7}$ D \\ 1 Department of Abdominal and General Surgery and Oncology, National Cancer Institute, 1 Santariskiu Str., \\ LT-08406 Vilnius, Lithuania \\ 2 Institute of Clinical Medicine, Faculty of Medicine, Vilnius University, LT-03101 Vilnius, Lithuania; \\ narimantas.samalavicius@gmail.com \\ 3 Department of Abdominal Surgery, Vilnius University Hospital Santaros Clinics, 2 Santariskiu Str., \\ LT-08661 Vilnius, Lithuania; gvytautas@gmail.com \\ 4 Laboratory of Cancer Epidemiology, National Cancer Institute, LT-08406 Vilnius, Lithuania; \\ inga.kildusiene@gmail.com (I.K.); giedre.smailyte@nvi.lt (G.S.) \\ 5 Department of Surgery, Klaipeda University Hospital, 41 Liepojos Str., LT-92288 Klaipeda, Lithuania \\ 6 Health Research and Innovation Science Center, Faculty of Health Sciences Klaipeda University, \\ 84 Herkaus Manto Str., LT-92294 Klaipeda, Lithuania \\ 7 Institute of Health Sciences, Faculty of Medicine, Vilnius University, LT-03101 Vilnius, Lithuania \\ * Correspondence: audrius.dulskas@gmail.com; Tel.: +37-067-520-094
}

Received: 18 October 2020; Accepted: 8 December 2020; Published: 14 December 2020

\begin{abstract}
Purpose: In this study, we analyzed the mortality and survival of colorectal cancer patients in Lithuania. Methods: This was a national cohort study. Population-based data from the Lithuanian Cancer Registry and period analyses were collected. Overall, 20,980 colorectal cancer patients were included. We examined the changes in colorectal cancer mortality and survival rates between 1998 and 2012 according to cancer anatomical sub-sites and stages. We calculated the 5-year relative survival estimates using period analysis. Results: Overall, 20,980 colorectal cancer cases reported from 1998 to 2012 were included in the study. The total number of newly diagnosed colorectal cancers increased from 1998-2002 to 2008-2012 by $12.1 \%$. The highest number of colorectal cancers was localized and increased from $33.9 \%$ to $42.0 \%$. The number of cancers with regional metastases and advanced cancers decreased by $11.1 \%$ and $15.5 \%$, respectively. An increased number of new cases was observed for almost all colon cancer sub-sites. The overall 5-year relative survival rate increased from $37.9 \%$ in $1998-2002$ to $51.5 \%$ in $2008-2012$. We showed an increase in survival rates for all stages and all sub-sites. In the most recent period, patients with a localized disease had a 5-year survival rate of $78.6 \%$, while survival estimates for advanced cancer patients remained low at $6.6 \%$. Conclusion: Although survival rates variated in colorectal cancer patients according to disease stages and sub-sites, we showed increased survival rates for all patients.
\end{abstract}

Keywords: colorectal cancer; colorectal cancer survival; national burden; Lithuanian cancer registry

\section{Introduction}

Worldwide, colon and rectal cancer is the third most commonly diagnosed cancer in males and the second in females [1]. Moreover, colorectal cancer is the second leading cause of cancer death in both sexes globally [1]. Its burden is expected to increase by $60 \%$ with more than 2.2 million new cases and 1.1 million cancer deaths by 2030 [2]. There is no effective primary prevention for colorectal cancer, but well-timed diagnosis, adequate staging and treatment can provide an excellent prognosis. A screening program allows doctors to diagnose the disease at earlier stages, thereby decreasing the 
mortality rate [3]. It is stated that colorectal cancer mortality decreased by $39.8 \%$ in men and $38.8 \%$ in women in the United States over the two last decades. In all 27 European Union member states, the decrease was slightly less: $13.0 \%$ and $27.0 \%$, accordingly [2]. In addition, the highest colorectal cancer mortality rates were in Central and Eastern Europe (15.2 per 100,000), compared to the lowest rates in South-Central Asia (3.6 per 100,000) and Polynesia (4.4 per 100,000) [4]. Survival and mortality rates are different among countries, and survival rates have improved with time [5]. In order to assess the real life changes in cancer prevalence and to audit the diagnostic and treatment efficiency, cancer registries are the best tools [6].

A colorectal cancer screening program started in Lithuania in 2009 (in the first two largest cities with a population constituting $35 \%$ of the whole country). The program consists of performing an occult blood test (iFOBT) every two years starting at age 50 (until age 74) and a colonoscopy if the latter is positive. Since 2014, the program has been run nationwide. The program coverage is around $50 \%$ of the population.

However, there is limited detail and homogenously collected data about colorectal cancer in Lithuania, so our present study aimed to analyze the survival of colorectal cancer patients from 1998 to 2012 in the Lithuanian population.

\section{Materials and Methods}

Ethical approval for the analysis of the population-based cancer registry data was not required.

The study was based on the Lithuanian Cancer Registry database, covering a population of less than 3 million residents, according to the 2018 census data. This database is a nationwide cancer registry containing personal, demographic and clinical information of all cancer patients in Lithuania since 1978. The registry is a part of the Cancer Incidence in Five Continents, which is a source of population-based cancer registries from all over the world [7]. In addition, it is possible to withdraw the death certificate for living status verification. The last date that a vital status assessment was conducted was on December 31, 2012. All data were anonymized before analysis.

In this study, we analyzed the survival of colorectal cancer (ICD-10 C18-C20, excluding large bowel lymphoma) patients diagnosed between 1998-2012. Cancer localization was assessed using the International Classification of Diseases ICD-O-3. We analyzed all the primary colorectal cancers. Aggregated sub-sites included the caecum and appendix (C18.0, C18.1); the right colon (C18.2, C18.3); the transverse colon (C18.4); the left colon (C18.5, C18.6, C18.7); other (C18.8, C18.9); and the rectosigmoid (C19) and rectum (C20).

Cancer stages drafted from the Lithuanian Cancer Registry were divided into three groups: (1) localized cancer T1-4/N0/M0; (2) advanced cancer with regional metastasis without distant spread: any $\mathrm{T} / \mathrm{N}+/ \mathrm{M} 0$; and (3) advanced cancer with distant spread: any $\mathrm{T} /$ any $\mathrm{N} / \mathrm{M}+$ [8]. When patients underwent surgical treatment, pathological staging was given. For clinical staging, a computed tomography scan of the chest, abdomen and pelvis was used or a chest x-ray with an ultrasound. For rectal cancer, pelvic magnetic resonance imaging was performed. If any of these were missing, the data were termed as "missing data".

Five-year relative survival estimates were calculated using period analysis. It provided more up-to-date survival estimates [9] Relative survival was calculated based on the ratio of the observed survival of cancer patients and the expected survival of the underlying general population. The latter was calculated according to the Ederer II method, using national life tables for the Lithuanian population stratified by age, gender and calendar year. The relative survival was adjusted for age using the international standard for cancer survival analysis. We performed the survival calculations with the freely available Stata statistical program [10].

\section{Results}

Overall, we included 20,980 colorectal cancer cases drafted from the Lithuanian Cancer Registry from 1998 to 2012. Table 1 shows cancer cases according to different time periods, cancer cases by sub-site and the extent of the disease. It also shows the differences between the time periods. 
Table 1. Distribution of the colorectal cancer cases considered in the analysis by period of diagnosis, subsite and extent of disease. Number of cases and percentage.

\begin{tabular}{|c|c|c|c|c|c|c|c|}
\hline & \multicolumn{2}{|c|}{ 1998-2002 } & \multicolumn{2}{|c|}{ 2003-2007 } & \multicolumn{2}{|c|}{ 2008-2012 } & \multirow{2}{*}{ Change $*, \%$} \\
\hline & Cases & $\%$ & Cases & $\%$ & Cases & $\%$ & \\
\hline \multicolumn{8}{|l|}{ Stage } \\
\hline Localized tumor T1-T4 & 2236 & 33.88 & 2824 & 40.46 & 3106 & 41.97 & 38.91 \\
\hline Tumor with regional spread $\mathrm{N}+$ & 2189 & 33.17 & 1968 & 28.20 & 1947 & 26.31 & -11.06 \\
\hline Advanced cancer with distant spread & 1762 & 26.70 & 1687 & 24.17 & 1489 & 20.12 & -15.49 \\
\hline Missing & 413 & 6.26 & 500 & 7.16 & 859 & 11.61 & 107.99 \\
\hline \multicolumn{8}{|l|}{ Subsite } \\
\hline Caecum and appendix (C180, C181) & 503 & 7.62 & 459 & 6.58 & 526 & 7.11 & 4.57 \\
\hline Right colon (C182, C183) & 604 & 9.15 & 685 & 9.82 & 814 & 11.00 & 34.77 \\
\hline Transverse colon (C184) & 368 & 5.58 & 351 & 5.03 & 329 & 4.45 & -10.60 \\
\hline Left colon $(\mathrm{C} 185, \mathrm{C} 186, \mathrm{C} 187)$ & 1741 & 26.38 & 1889 & 27.07 & 2107 & 28.47 & 21.02 \\
\hline Other $(\mathrm{C} 188, \mathrm{C} 189)$ & 194 & 2.94 & 288 & 4.13 & 283 & 3.82 & 45.88 \\
\hline Rectosigmoid (C19) & 376 & 5.70 & 450 & 6.45 & 507 & 6.85 & 34.84 \\
\hline Rectum (C20) & 2814 & 42.64 & 2857 & 40.94 & 2835 & 38.31 & 0.75 \\
\hline All cases & 6600 & 100.00 & 6979 & 100.00 & 7401 & 100.00 & 12.14 \\
\hline
\end{tabular}

The total number of newly diagnosed colorectal cancers increased from 1998-2002 to 2008-2012 by $12.1 \%$ (from 5207 to 5950 cases, respectively). Most of colorectal cancers were localized and increased from 33.9 to $42.0 \%$. The number of cancers with regional metastases and advanced cancers decreased by $11.1 \%$ and $15.5 \%$, respectively. An increased number of new cases was observed for almost all colon cancer sub-sites, with little change in the number of rectosigmoid and rectal cancers.

The overall 5-year relative survival rate increased from $37.9 \%$ in $1998-2002$ to $51.5 \%$ in $2008-2012$ (Table 2). Better survival rates were seen for all disease stages and all sub-sites (Figures 1-3). In the most recent period, patients with a localized disease had a 5 -year survival rate of $78.6 \%$, while survival estimates for advanced cancer remained low at $6.6 \%$. Survival rates varied little by sub-site. The 5-year relative survival rate was slightly over $50 \%$ for colon cancer patients and almost $50 \%$ for rectal cancer patients in the period between 2008-2012.

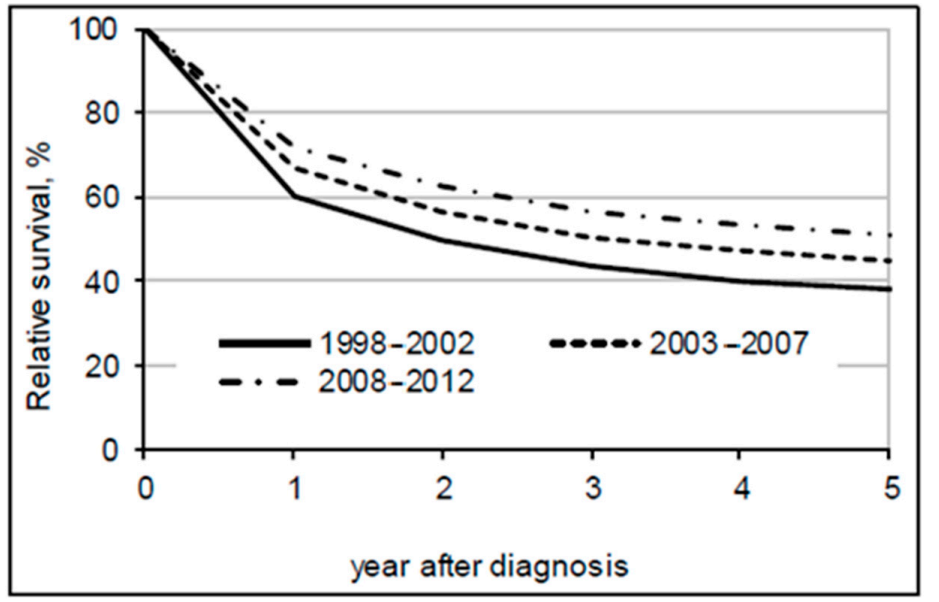

Figure 1. Five-year relative survival of colorectal cancer patients by period of diagnosis. 
Table 2. Five-year relative survival and $95 \%$ confidence interval by period of diagnosis, subsite and extent of disease.

\begin{tabular}{|c|c|c|c|c|}
\hline & 1998-2002 & $2003-2007$ & 2008-2012 & Change $* \%$ \\
\hline \multicolumn{5}{|l|}{ Stage } \\
\hline Tumor localized T1-T4 & $\begin{array}{c}66.07 \\
(63.45-68.62)\end{array}$ & $\begin{array}{c}70.84 \\
(68.39-73.23)\end{array}$ & $\begin{array}{c}78.60 \\
(76.33-80.80)\end{array}$ & 12.53 \\
\hline Advanced tumor with regional spread $\mathrm{N}+$ & $\begin{array}{c}40.25 \\
(37.98-42.54)\end{array}$ & $\begin{array}{c}49.24 \\
(46.57-51.89)\end{array}$ & $\begin{array}{c}52.36 \\
(49.57-55.14)\end{array}$ & 12.11 \\
\hline Advanced cancer with distant spread & $\begin{array}{c}4.53 \\
(3.62-5.60)\end{array}$ & $\begin{array}{c}6.61 \\
(5.40-7.99)\end{array}$ & $\begin{array}{c}6.77 \\
(5.47-8.25)\end{array}$ & 2.24 \\
\hline Missing & $\begin{array}{c}26.74 \\
(22.56-31.16)\end{array}$ & $\begin{array}{c}22.36 \\
(18.39-26.66)\end{array}$ & $\begin{array}{c}29.02 \\
(25.02-33.21)\end{array}$ & 2.28 \\
\hline \multicolumn{5}{|l|}{ Subsite } \\
\hline Caecum and appendix (C18.0, C18.1) & $\begin{array}{c}35.71 \\
(31.05-40.49)\end{array}$ & $\begin{array}{c}50.38 \\
(44.65-56.04)\end{array}$ & $\begin{array}{c}52.13 \\
(46.60-57.59)\end{array}$ & 16.42 \\
\hline Right colon (C18.2, C18.3) & $\begin{array}{c}43.22 \\
(38.58-47.88)\end{array}$ & $\begin{array}{c}51.33 \\
(46.54-56.08)\end{array}$ & $\begin{array}{c}52.95 \\
(48.38-57.47)\end{array}$ & 9.73 \\
\hline Transverse colon (C18.4) & $\begin{array}{c}43.53 \\
(37.78-49.30)\end{array}$ & $\begin{array}{c}41.20 \\
(35.12-47.38)\end{array}$ & $\begin{array}{c}52.39 \\
(45.73-58.93)\end{array}$ & 8.86 \\
\hline Left colon $(\mathrm{C} 18.5, \mathrm{C} 18.6, \mathrm{C} 18.7)$ & $\begin{array}{c}45.77 \\
(43.01-48.52)\end{array}$ & $\begin{array}{c}46.65 \\
(43.92-49.37)\end{array}$ & $\begin{array}{c}54.12 \\
(51.32-56.89)\end{array}$ & 8.35 \\
\hline Other $(\mathrm{C} 18.8, \mathrm{C} 18.9)$ & $\begin{array}{c}10.84 \\
(8.00-14.20)\end{array}$ & $\begin{array}{c}24.34 \\
(18.49-30.84)\end{array}$ & $\begin{array}{c}26.40 \\
(20.60-32.72) \\
\end{array}$ & 15.56 \\
\hline Rectosigmoid (C19) & $\begin{array}{c}31.62 \\
(26.47-37.01)\end{array}$ & $\begin{array}{c}42.39 \\
(36.76-48.07)\end{array}$ & $\begin{array}{c}57.26 \\
(51.26-63.10)\end{array}$ & 25.64 \\
\hline Rectum (C20) & $\begin{array}{c}35.61 \\
(33.62-37.63)\end{array}$ & $\begin{array}{c}44.49 \\
(42.23-46.74)\end{array}$ & $\begin{array}{c}49.59 \\
(47.32-51.86)\end{array}$ & 13.98 \\
\hline All cases & $\begin{array}{c}37.86 \\
(36.54-39.19)\end{array}$ & $\begin{array}{c}45.04 \\
(43.60-46.48)\end{array}$ & $\begin{array}{c}51.13 \\
(49.67-52.58)\end{array}$ & 13.27 \\
\hline
\end{tabular}

* percent units change in survival compared to the period 1998-2002.
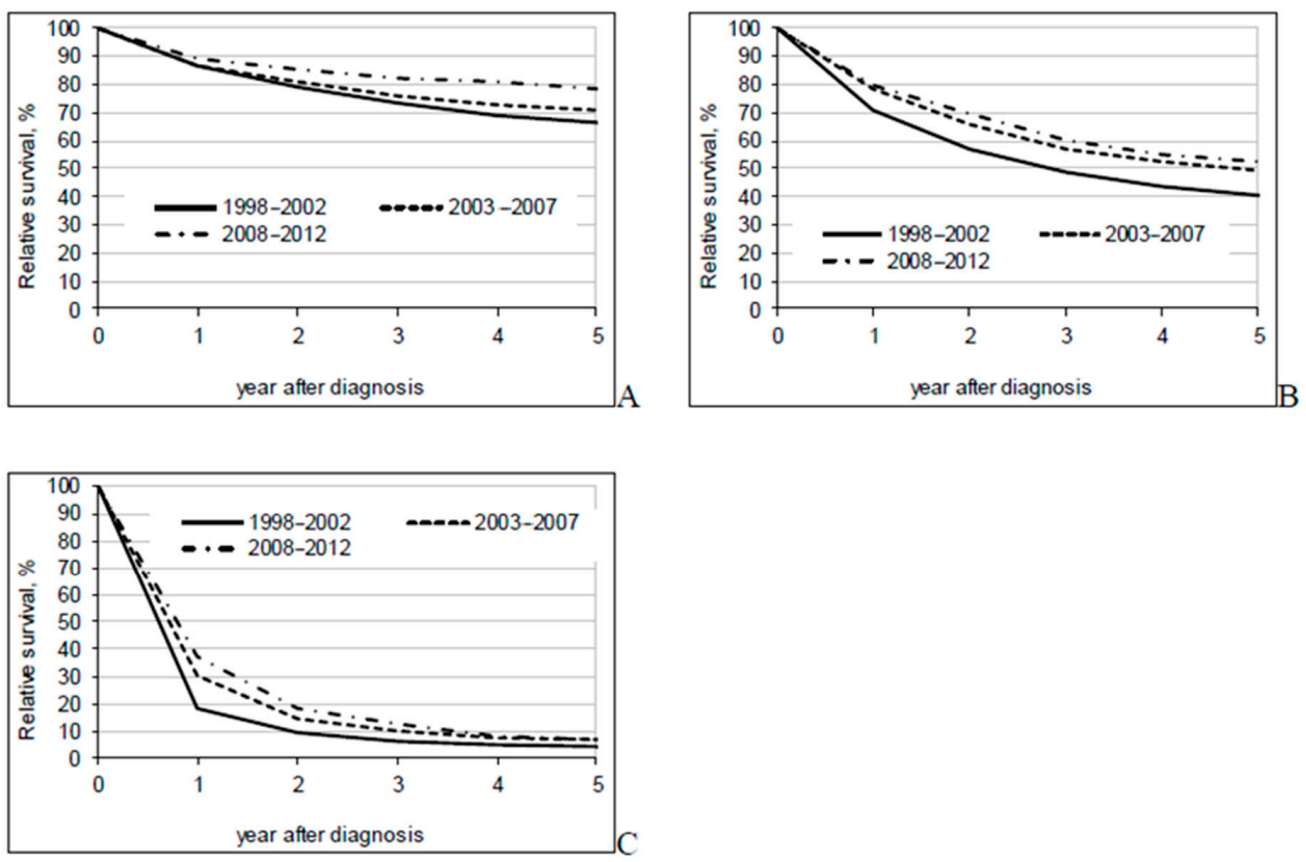

Figure 2. Five-year relative survival by period of diagnosis and extent of disease ((A)_localized; (B)_regional metastases; (C)—advanced). 

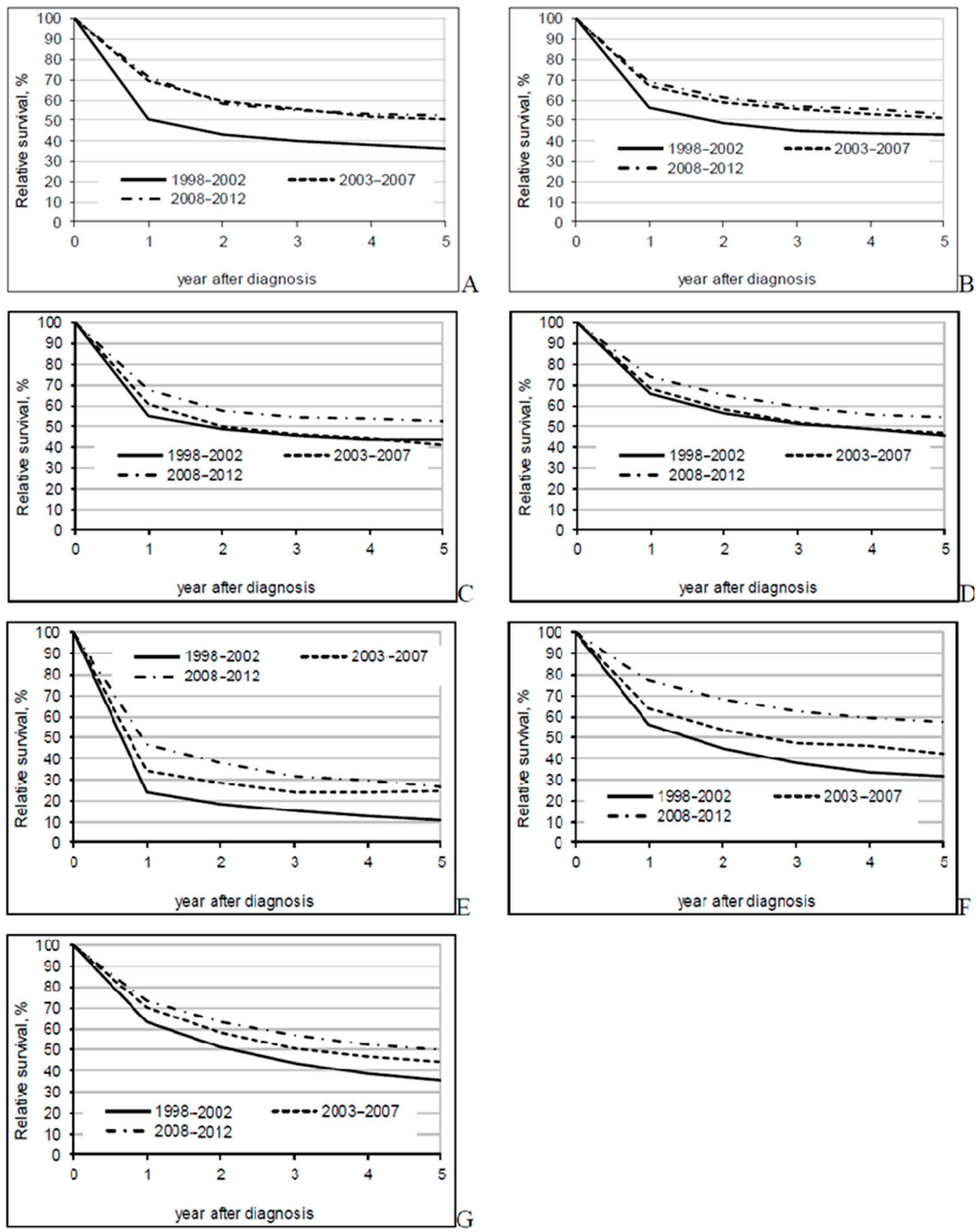

Figure 3. Five-year relative survival by period of diagnosis and extent of disease (A) - caecum and appendix; (B)—right colon; (C)—transversum; (D)—left colon; (E)—other; (F)—rectosigmoid; (G)-rectum).

\section{Discussion}

This is the first study to assess colorectal cancer survival in Lithuania over three different time periods by stage at diagnosis and cancer sub-site. Here, we showed that survival rates have improved significantly in Lithuania in colorectal cancer patients. There are many possible explanations for this improvement. First of all, the introduction of a regional bowel screening program (fecal occult 
blood test (iFOBT) performed every two years and a colonoscopy if the latter is positive) in Lithuania in 2009 (started in the capital city) may explain the slight increase in colorectal cancer incidence. The 5-year colorectal cancer survival rate in Lithuania has increased modestly over the past 14 years and is expected to increase further because of the screening program implemented nationwide in 2014. This national program has resulted in earlier diagnosis, possibly better treatment and survival options. Moreover, a further screening program test through a colonoscopy is important and its benefits are complex. An endoscopy is supposed to diagnose colorectal cancer earlier, but it also prevents cancer by removing the precursor lesions or adenomas [11].

It is important to note that, in the late 1990s, Lithuania changed the health system funding from local budgets (when it was very hard for a patient to reach a tertiary hospital center without paying additional money, and not all patients received proper health care) to a mixed system, mainly funded by the National Health Insurance Fund (NHIF). The Lithuanian health care system is thought to serve the whole population, and all residents have to pay for the health insurance scheme (typically paying $6-9 \%$ of taxable income). All residents pay the same amount of money and all should receive free health care [12].

Other important factors that may improve survival are minimal invasive surgical techniques, better perioperative care, the centralization of hospitals that operate on colorectal cancer and multidisciplinary team meetings for patients with advanced stages [13-15]. In addition to this, colorectal specialists, compared to when general surgeons performed surgeries, treat a higher numbers of colonic resections. Another important factor is the wider use of neoadjuvant chemo-radiotherapy in advanced rectal cancer [16-20]. Adjuvant chemotherapy in stages II and III of colon cancer has shown to increase survival by $5-15 \%$ in randomized trials [21]. Nevertheless, complete mesocolic excision and central vascular ligation have been emphasized recently, although data are opposing [22-24].

Overall, survival rate improvement was seen in most cancer sites, including colorectal [25]. The present results show that the survival rates of colorectal cancer patients in Lithuania $(51.5 \%)$ are worse than the rates observed in Northern (Norway, 63.4\% and Sweden, 60.3\%) and Central European countries (Germany, $61.4 \%$ and Denmark, $63 \%$ colon and $65 \%$ rectal cancer) over similar time periods $[5,14,26,27]$ and other Western countries (e.g., United States, $64.1 \%$ and United Kingdom, $53.1 \%)[28,29]$.

Although mortality is decreasing, the incidence of colorectal cancer is rising. It is known that colorectal cancer correlates with economic status and lifestyle choices, including the consumption of fatty fast food, smoking, a lack of physical activity and obesity [25]. This Westernization of lifestyle choices is becoming more common in Lithuania today. Moreover, the incidence of colorectal cancer cases has been declining in some Western countries, including the United States, France and Australia [29]. Although the difference is often attributed to the adoption of a Western lifestyle and the long-term effects of screening for colorectal cancer, no concluding explanation currently exists [29,30]. Although colorectal cancer incidence is lower in less developed regions of the world, mortality is higher, with the highest mortality rate in Eastern Europe (15.2:100.000) [4].

We have also noticed changes in treatment over time. In Lithuania, minimal invasive treatment is gaining more popularity and, since 2010, the penetration of laparoscopic surgery is more than $30-40 \%$. Since 2010, complete mesocolic excision became a standard of care in colon cancer treatment. Furthermore, intensified treatment of advanced colorectal cancer with distant spread has also increased survival worldwide [31]. Differently from other studies, we did not see a survival improvement in advanced diseases with distant spread over the years (it has risen from 4 to $6 \%$ only). There could be a few explanations for this lack of improvement. First, supplementary nutrition is not reimbursed in Lithuania, and most patients are unfit for aggressive systemic treatment. Second, patients have refused the treatment, stating that it will not prolong their survival. Third, there is a lack of the newest systemic therapy agents on the Lithuanian market (due to difficulties with reimbursement) and the only possibility of receiving novel treatment is under international clinical trial. Contrary to another study [24], rectal cancer patients had a significantly better 5-year survival rate (66.2\%) compared to 
colon cancer patients $(52.4 \% ; p \leq 0.05)$. In our study, the 5-year relative survival rate was slightly higher than $50 \%$ for patients with colon cancer and almost $50 \%$ for patients with rectal cancer in the period between 2008-2012. The reason for this difference is that rectal cancer surgeries are still partly performed by general surgeons without MDT meeting discussions, omitting neoadjuvant treatment. The centralization of colorectal cancer started only in 2018, and we do not have any results yet.

Our study is the first and largest population-based study comparing cancer survival rates in Lithuania. However, this study had several limitations. Analysis was limited by variables in the database. We believe that additional patient information, such as co-morbidities, body mass index, lifestyle, multiple treatment modalities used and socioeconomic status, would have enabled analysis that was more thorough. In addition, we did not exclude the appendiceal cancers from the analysis, which represent a more distinct entity and often have different histology. However, these cancers consist in very few cases.

\section{Conclusions}

To conclude, we have shown that outcomes of colorectal cancer in Lithuania are comparable to international standards. Although survival rates variated in colorectal cancer patients according to disease stages and sub-sites, increased survival was evident for all patients, especially in patients with a localized disease. The 5-year survival was $78.6 \%$, while survival estimates for advanced cancer remained low at $6.6 \%$. Earlier detection and better treatment were likely the causes of these changes.

Author Contributions: N.E.S., V.G., I.K., G.S. and A.D. contributed to this work, satisfying the following four criteria in the guidelines of the International Committee of Medical Journal Editors (ICMJE): substantial contributions to the conception or design of the work, or the acquisition, analysis or interpretation of data for the work; drafting the work or revising it critically for important intellectual content; final approval of the version to be published; agreement to be accountable for all aspects of the work in ensuring that questions related to the accuracy or integrity of any part of the work are appropriately investigated and resolved. All authors have read and agreed to the published version of the manuscript.

Funding: This research received no external funding

Conflicts of Interest: The authors declare that no conflicts of interest exist. The authors declare that they have no competing interests. The authors alone are responsible for the content and writing of the paper. The authors declare that this video vignette has not been published elsewhere and that it has not been submitted previously for publication elsewhere.

\section{References}

1. Bray, F.; Ferlay, J.; Soerjomataram, I.; Siegel, R.L.; Torre, L.A.; Jemal, A. Global Cancer Statistics 2018: GLOBOCAN estimates of incidence and mortality worldwide for 36 cancers in 185 countries. CA Cancer J. Clin. 2018, 68, 394-424. [CrossRef]

2. Ouakrim, D.A.; Pizot, C.; Boniol, M.; Malvezzi, M.; Boniol, M.; Negri, E.; Bota, M.; Jenkis, M.A.; Bielberg, H.; Autier, P. Trends in colorectal cancer mortality in Europe: Retrospective analysis of the WHO mortality database. BMJ 2015, 351, h4970. [CrossRef]

3. Haggar, F.A.; Boushey, R.P. Colorectal cancer epidemiology: Incidence, mortality, survival, and risk factors. Clin. Colon Rectal Surg. 2009, 22, 191-197. [CrossRef]

4. International Agency for Research on Cancer. Global Cancer Observatory: Cancer Today, Lyon, France. 2018. Available online: https://gco.iarc.fr/today (accessed on 15 December 2019).

5. Brenner, H.; Bouvier, A.M.; Foschi, R.; Hackl, M.; Larsen, I.K.; Lemmens, V.; Mangone, L.; Francisci, S.; The EUROCARE Working Group. Progress in colorectal cancer survival in Europe from the late 1980s to the early 21st century: The EUROCARE study. Int. J. Cancer 2012, 131, 1649-1658. [CrossRef]

6. Berrino, F.; Verdecchia, A.; Lutz, J.M.; Lombardo, C.; Micheli, A.; Capocaccia, R.; The EUROCARE Working Group. Comparative cancer survival information in Europe. Eur. J. Cancer 2009, 45, 901-908. [CrossRef] [PubMed] 
7. Bray, F.; Ferlay, J.; Laversanne, M.; Brewster, D.H.; Gombe Mbalawa, C.; Kohler, B.; Piñeros, M.; Steliarova-Foucher, E.; Swaminathan, R.; Antoni, S.; et al. Cancer Incidence in Five Continents: Inclusion criteria, highlights from Volume $X$ and the global status of cancer registration. Int. J. Cancer 2015, 137, 2060-2071. [CrossRef]

8. Brierley, J.D.; Gospodarowicz, M.K.; Wittekind, C. (Eds.) The TNM Classification of Malignant Tumours, 8th ed.; Wiley Blackwell: Oxford, UK, 2017.

9. Brenner, H.; Gefeller, O.; Hakulinen, T. Period analysis for providing more up-to-date cancer survival data: Theory, empirical evaluation, computational realization and applications. Eur. J. Cancer 2004, 40, 326-335. [CrossRef]

10. Dickman, P.W. Estimating and Modelling Relative Survival Using Stata. Available online: http://www. pauldickman.com/rsmodel/stata_colon/ (accessed on 15 January 2020).

11. Issa, I.A.; Noureddine, M. Colorectal cancer screening: An updated review of the available options. World J. Gastroenterol. 2017, 23, 5086-5096. [CrossRef] [PubMed]

12. Murauskiene, L.; Janoniene, R.; Veniute, M.; van Ginneken, E.; Karanikolos, M. Lithuania: Health system review. Health Syst. Transit. 2013, 15, 1-150.

13. Kodeda, K.; Johansson, R.; Zar, N.; Birgisson, H.; Dahlberg, M.; Skullman, S.; Lindmark, G.; Glimelius, B.; Påhlman, L.; Martling, A. Time trends, improvements and national auditing of rectal cancer management over an 18- year period. Colorectal Dis. 2015, 17, 168-179. [CrossRef]

14. Guren, M.G.; Kørner, H.; Pfeffer, F.; Myklebust, T.Å.; Eriksen, M.T.; Edna, T.-H.; Larsen, S.G.; Knudsen, K.O.; Nesbakken, A.; Wasmuth, H.H.; et al. Nationwide improvement of rectal cancer treatment outcomes in Norway, 1993-2010. Acta Oncol. 2015, 54, 1714-1722. [CrossRef] [PubMed]

15. Borowski, D.W.; Bradburn, D.M.; Mills, S.J.; Bharathan, B.; Wilson, R.G.; Ratcliffe, A.A.; Kelly, S.B. Volume-outcome analysis of colorectal cancer-related outcomes. Br. J. Surg. 2010, 97, 1416-1430. [CrossRef] [PubMed]

16. van Steenbergen, L.N.; Elferink, M.A.; Krijnen, P.; Lemmens, V.E.P.P.; Siesling, S.; Rutten, H.J.T.; Richel, D.J.; Karim-Kos, H.E.; Coebergh, J.W.W.; on the behalf of the Working Group Output of The Netherlands Cancer Registry. Improved survival of colon cancer due to improved treatment and detection: A nationwide population-based study in The Netherlands 1989-2006. Ann. Oncol. 2010, 21, 2206-2212. [CrossRef]

17. Andre, T.; Boni, C.; Navarro, M.; Tabereno, M.; Hickish, T.; Topham, C.; Bonetti, A.; Clingan, P.; Bridgewater, J.; Rivera, F.; et al. Improved overall survival with oxaliplatin, fluorouracil, and leucovorin as adjuvant treatment in stage II or III colon cancer in the MOSAIC trial. J. Clin. Oncol. 2009, 27, 3109-3116. [CrossRef]

18. Andre, T.; de Gramont, A.; Vernerey, D.; Chibaudel, B.; Bonnetain, F.; Tijeras-Raballand, A.; Scriva, A.; Hickish, T.; Tabernero, J.; Van Laethem, J.L.; et al. Adjuvant fluorouracil, leucovorin, and oxaliplatin in stage II to III colon cancer: Updated 10-year survival and outcomes according to BRAF mutation and mismatch repair status of the MOSAIC study. J. Clin. Oncol. 2015, 33, 4176-4187. [CrossRef]

19. Glimelius, B.; Grönberg, H.; Järhult, J.; Wallgren, A.; Cavallin-ståhl, E. A systematic overview of radiation therapy effects in rectal cancer. Acta Oncol. 2003, 42, 476-492. [CrossRef]

20. Braendengen, M.; Tveit, K.M.; Berglund, Å.; Birkemeyer, E.; Frykholm, G.; Påhlman, L.; Wiig, J.N.; Byström, P.; Bujko, K.; Glimelius, B. Randomized phase III study comparing preoperative radiotherapy with chemoradiotherapy in nonresectable rectal cancer. J. Clin. Oncol. 2008, 26, 3687-3694. [CrossRef]

21. West, N.P.; Hohenberger, W.; Weber, K.; Perrakis, A.; Finan, P.J.; Quirke, P. Complete mesocolic excision with central vascular ligation produces an oncologically superior specimen compared with standard surgery for carcinoma of the colon. J. Clin. Oncol. 2010, 28, 272-278. [CrossRef]

22. Olofsson, F.; Buchwald, P.; Elmståhl, S.; Syk, I. Wide excision in rightsided colon cancer is associated with decreased survival. Scand. J. Surg. 2013, 102, 241-245. [CrossRef]

23. Allemani, C.; Weir, H.K.; Carreira, H.; Harewood, R.; Spika, D.; Wang, X.-S.; Bannon, F.; Ahn, A.V.; Johnson, C.J.; Bonaventure, A.; et al. Global surveillance of cancer survival 1995-2009: Analysis of individual data for 25, 676, 887 patients from 279 population-based registries in 67 countries (CONCORD-2). Lancet 2015, 385, 977-1010. [CrossRef]

24. Buchwald, P.; Hall, C.; Davidson, C.; Dixon, L.; Dobbs, B.; Robinson, B.; Frizelle, F. Improved survival for rectal cancer compared to colon cancer: The four cohort study. ANZ J. Surg. 2018, 88, E114-E117. [CrossRef] [PubMed] 
25. Arnold, M.; Sierra, M.S.; Laversanne, M.; Soerjomatram, I.; Jemal, A.; Bray, F. Global patterns and trends in colorectal cancer incidence and mortality. Gut 2017, 66, 683-691. [CrossRef] [PubMed]

26. Brenner, H.; Schrotz-King, P.; Holleczek, B.; Katalinic, A.; Hoffmeister, M. Declining Bowel Cancer Incidence and Mortality in Germany. Deutsches Ärzteblatt Int. 2016, 113, 101-106.

27. Iversen, L.H.; Green, A.; Ingeholm, P.; Østerlind, K.; Gögenur, I. Improved survival of colorectal cancer in Denmark during 2001-2012-The efforts of several national initiatives. Acta Oncol. 2016, 55 (Suppl. 2), 10-23. [CrossRef] [PubMed]

28. Joseph, D.A.; Johnson, C.J.; White, A.; Wu, M.; Coleman, M.P. Rectal cancer survival in the United States by race and stage, 2001 to 2009: Findings from the CONCORD-2 study. Cancer 2017, 123 (Suppl. 24), 5037-5058. [CrossRef] [PubMed]

29. Brouwer, N.P.M.; Bos, A.C.R.K.; Lemmens, V.E.P.P.; Tanis, P.J.; Nagtegaal, I.D.; de Wilt, J.H.W.; Verhoeven, R.H.A. An overview of 25 years of incidence, treatment and outcome of colorectal cancer patients. Int. J. Cancer 2018, 143, 2758-2766. [CrossRef]

30. Siegel, R.L.; Fedewa, S.A.; Anderson, W.F.; Miller, J.M.; Rosenberg, P.S.; Jemal, A. Colorectal cancer incidence patterns in the United States, 1974-2013. J. Natl. Cancer Inst. 2017, 109, 1-6. [CrossRef]

31. American Cancer Society. Survival Rates for Colorectal Cancer. Available online: https://www.cancer.org/ cancer/colon-rectal-cancer/detection-diagnosis-staging/survival-rates.html (accessed on 15 December 2019).

Publisher's Note: MDPI stays neutral with regard to jurisdictional claims in published maps and institutional affiliations. 